\title{
26. A SEISMIC REFLECTION PROFILE BETWEEN THE BONIN TRENCH AND $160^{\circ} \mathrm{E}$
}

\author{
Thomas A. Davies, Scripps Institution of Oceanography, La Jolla, California
}

\section{INTRODUCTION}

On November 14, 1970, Scripps Institution of Oceanography's research vessel Thomas Washington departed on a 9-month exploration of the Pacific Ocean. The expedition, which was designated ARIES, encompassed biological, chemical, and physical oceanographic studies and marine geological and geophysical investigations. The scientific program for Leg VII of ARIES (July 17 to August $30,1971)$ consisted of marine geological and geophysical investigations of the western North Pacific between Yokohama (Japan) and Honolulu (Hawaii). Special attention was focused on the area around the intersection of the Hawaiian and Emperor seamount chains and on the Hess Rise. Results of these studies are presented elsewhere (Davies, et al., 1971; Clague and Greenslate, 1972; Davies et al., 1972; Clague and Dalrymple, 1973). In addition, some of the data gathered by ARIES Leg VII were used in site selection for Leg 20 of the Deep Sea Drilling Project. Records from two portions of the ARIES Leg VII track were obtained expressly for Glomar Challenger Leg 20: the track from the Bonin Trench out to Makarov Seamount and a site survey conducted around $161^{\circ} 00^{\prime} \mathrm{E}, 28^{\circ} 40^{\prime} \mathrm{N}$ (see Figure 1). The purpose of this short contribution is to present these data. Readers wishing to have more information concerning ARIES Leg VII may contact T. A. Davies or the Geologic Data Center at Scripps Institution of Oceanography, with whom the data are lodged.

While underway on ARIES Leg VII, continuous records were made of depth (Gifft Depth Recorder) and total magnetic field (Varian magnetometer). Over most of the track seismic reflection records were also obtained, using a Bolt airgun system and an SIO hydrophone array connected through a Bolt amplifier and Krohnhite filters to an Edo Western Mark XV recorder. Navigation was controlled by an IT\&T satellite navigation system, supplemented by celestial navigation and LORAN positioning. An IBM 1800 computer handled the software associated with the satellite navigation and provided continuous on-line navigational plots, as well as being used for routine data processing and smooth track plotting.

The ARIES expedition was supported by the Office of Naval Research and the National Science Foundation. In particular, Leg VII was supported in part by NSF Grant GA-30128 (T.A. Davies, Principal Investigator). This support is gratefully acknowledged. The support of the technicians and of Captain Ferris and the officers and crew of $\mathrm{R} / \mathrm{V}$ Thomas Washington is greatly appreciated. The author would also like to thank B.C. Heezen for his assistance in assembling this short contribution.

\section{BONIN TRENCH TO MAKAROV SEAMOUNT}

Data gathered by R/V Thomas Washington along a track across the Bonin Trench and east to Makarov Seamount were utilized by D/V Glomar Challenger in the selection of Sites 195, 196, and 197. The track of R/V Thomas Washington through this part of the western North Pacific is shown in Figures 2 to 4 and seismic reflection profiles in Figures 5 to 14 .

The upper transparent layer provides a sufficient thickness of soft sediment to permit spudding in throughout this traverse. A refelctor about $0.8 \mathrm{sec}$ below the sea floor appears (Figure 11) beneath the deepest part of the Pacific basin. Since such deep penetration had not previously been reported, careful consideration was given to the possibility that the smooth deep reflection might be an artifact of the instrumentation, or a multiple echo, but no obvious explanation of that type was found. Drilling at Site 196 established that the sediments extend well beneath the first reflections, but drilling was ended at 377 meters by a worn-out bit before the deeper parts of the section had been reached. Thus, the deepest horizon recorded appears to be a valid reflection from an acoustostratigraphic horizon. Its smoothness suggests the occurrence of deeper sedimentary layers.

DSDP Site 197 reached basalt, confirming the interpretation of the possible elevated feature shown in Figure 11 as a basement high.

\section{DEEP SEA DRILLING SITE SURVEY}

Deep Sea Drilling Project proposed Site No. 2 for Leg 20 was surveyed on August 2 and 3,1971. The site had been proposed by the JOIDES Pacific Advisory Panel in a region that was believed to be generally flat with a regional depth of about 3000 fathoms, and at the one locality, $161^{\circ} 00^{\prime} \mathrm{E}$, $28^{\circ} 40^{\prime} \mathrm{N}$, where there appeared to be sufficient soft superficial sediment to allow the drill to spud in properly before striking harder rock.

A bathymetric sketch of the region based on survey work from R/V Thomas Washington is shown in Figure 15. It is now clear that the area is far from flat, but rather, is covered by low rolling hills. Further, the seismic reflection profiles (Figure 16) show that the acoustically transparent superficial sediment layer, up to $0.05 \mathrm{sec}$ thick on the airgun records, is quite widespread, generally appearing to fill the valleys and to be absent from the tops of the hills and the steeper slopes.

A piston core (ARIES 40PG) was taken at the locality originally proposed. This yielded only unfossiliferous, uniform brown clay. 


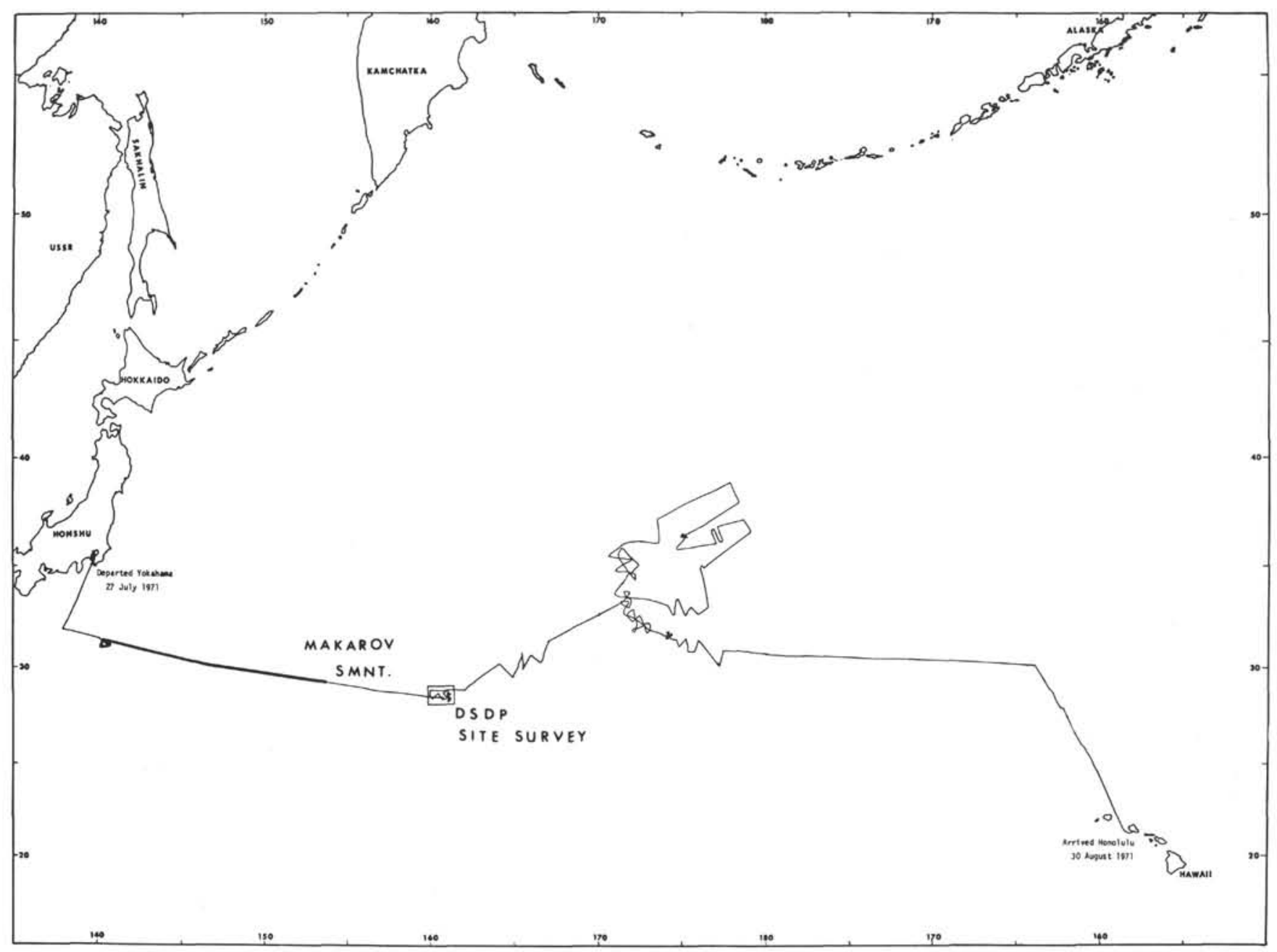

Figure 1. Track of $R / V$ Thomas Washington during ARIES, Leg VII.

Unfortunately, shortage of time precluded this site being drilled by Glomar Challenger (see report on Site 198, this volume).

\section{REFERENCES}

Clague, D. A. and Dalrymple, G. B., 1973. Age of Koko Seamount, Emperor seamount chain: Earth Planet. Sci. Lett., v. 17, p. 411-415.
Clague, D. A. and Greenslate, J., 1972. Alkali volcanic suite from the Emperor Seamounts (abstract): Geol. Soc. Am. 68th Ann. Meeting., Cordilleran Section, Abst. with Programs, v. 4, p. 136.

Davies, T. A., Clague, D. A., and Wilde, P., 1971. Preliminary report on Leg VII of ARIES Expedition: geological investigations in the western North Pacific, July-August, 1971: S.I.O. Ref. Ser., 71-27.

Davies, T. A., Wilde, P., and Clague, D. A., 1972 'Koko Seamount: a major guyot at the southern end of the Emperor seamounts: Marine Geol., v. 13, p. 311-321. 


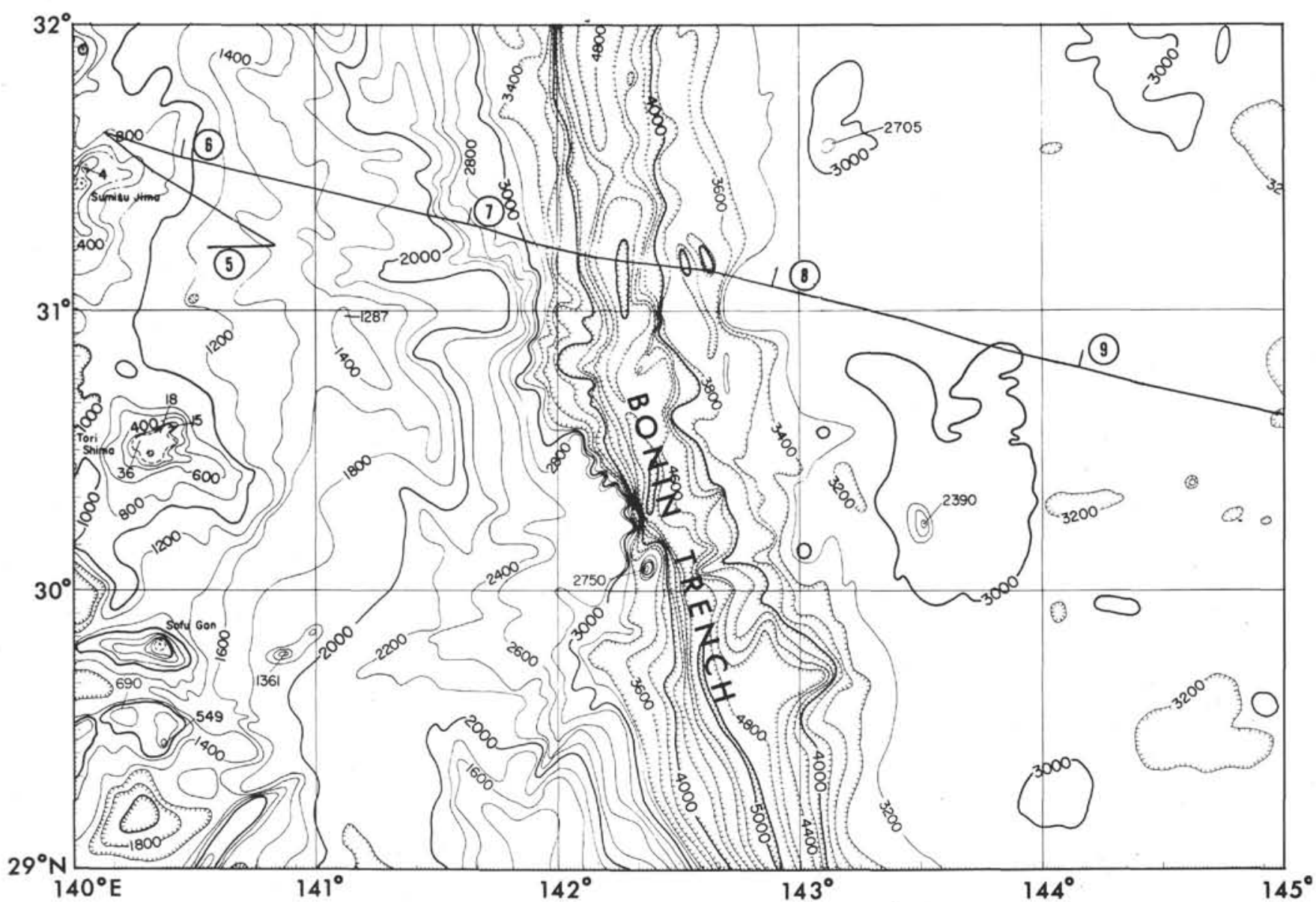

Figure 2. Detailed track of $R / V$ Thomas Washington from Sumisu Jima to $145^{\circ}$ E. Numbers along track refer to Figures 5 to 14. 
T. A. DAVIES

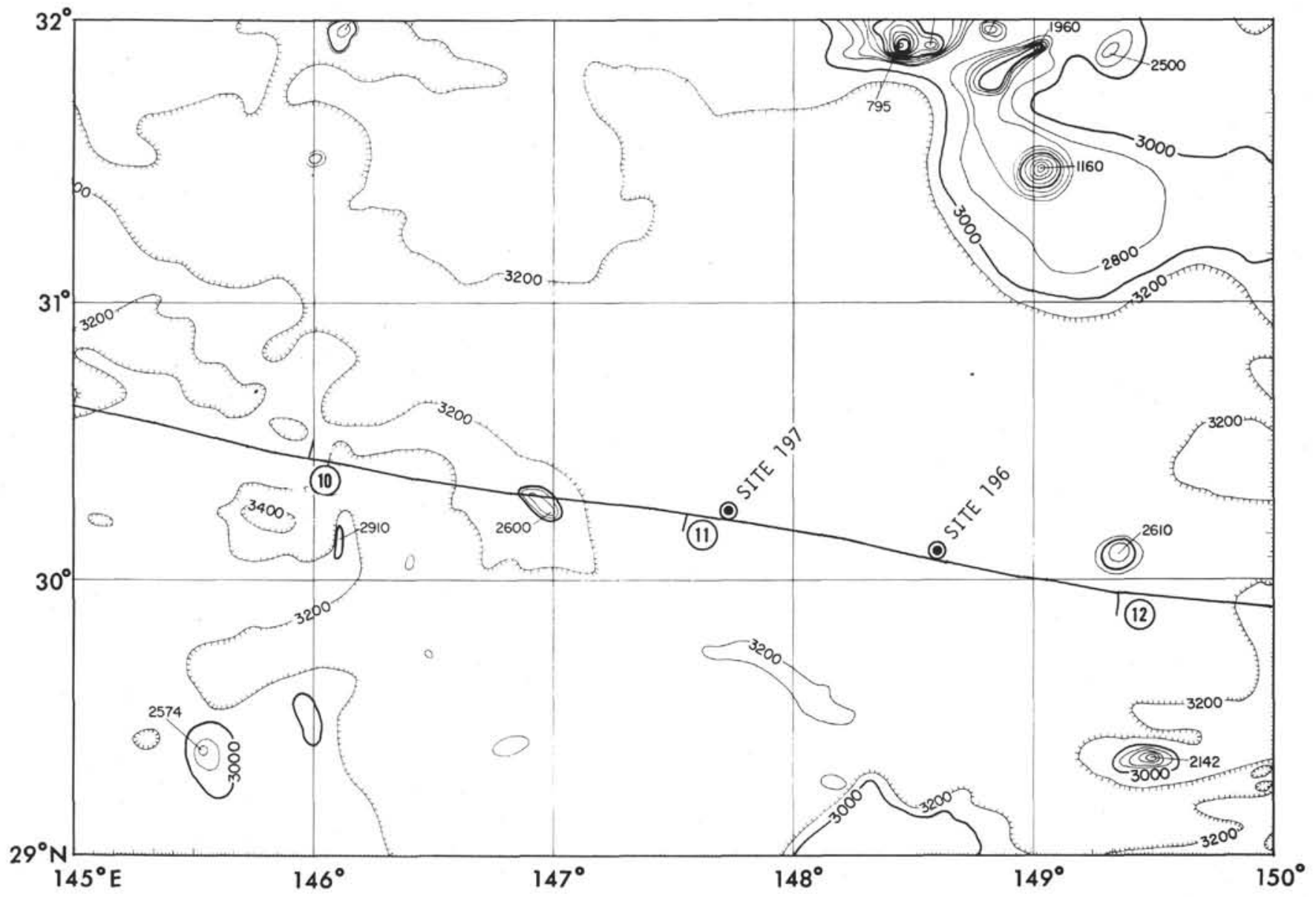

Figure 3. Detailed track of $R / V$ Thomas Washington from $145^{\circ}$ to $150^{\circ}$ E. Numbers along track refer to Figures 5 to 14 . 


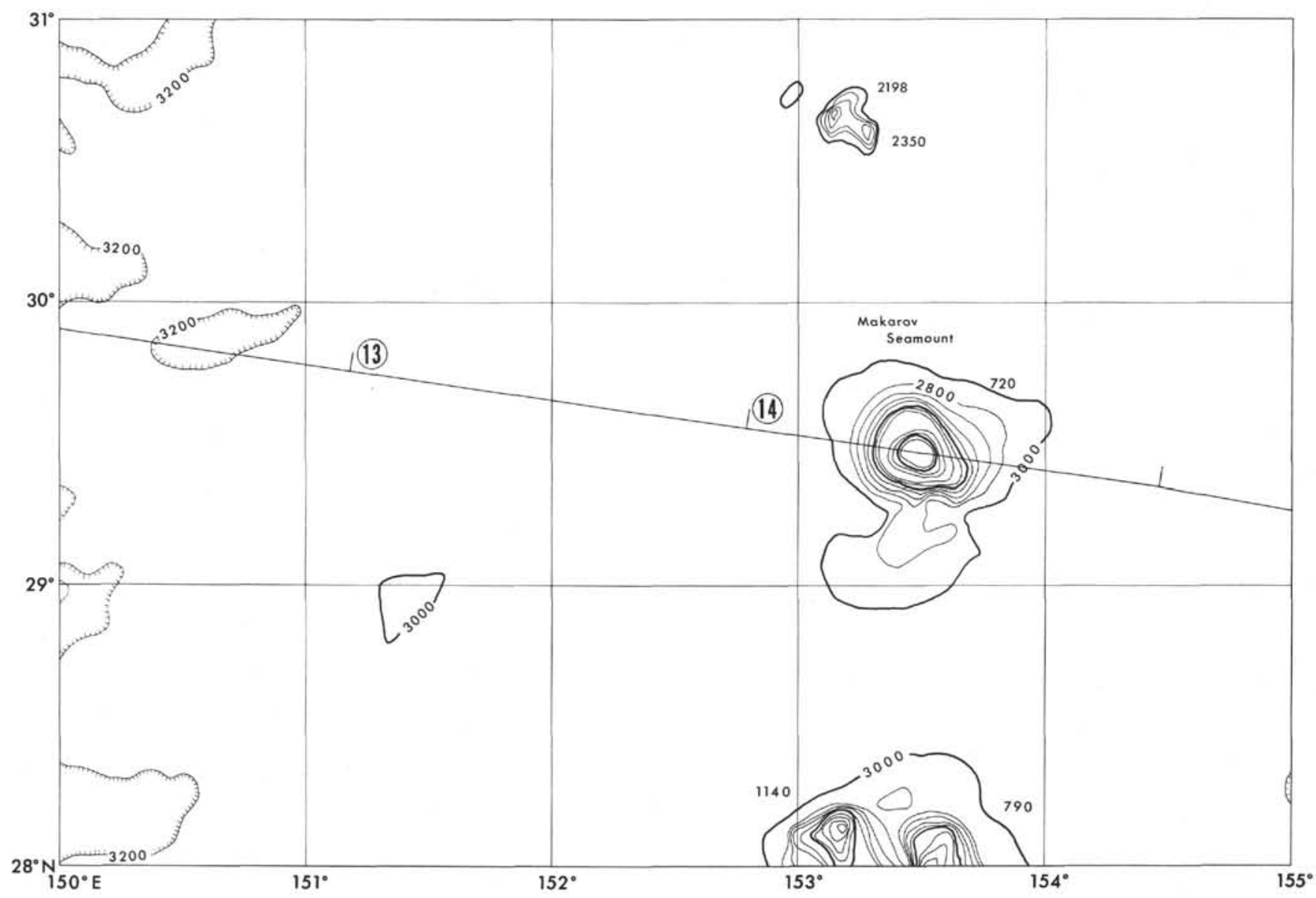

Figure 4. Detailed track of $R / V$ Thomas Washington from $150^{\circ}$ to $155^{\circ}$ E. Numbers along track refer to Figures 5 to 14 . 
T. A. DAVIES

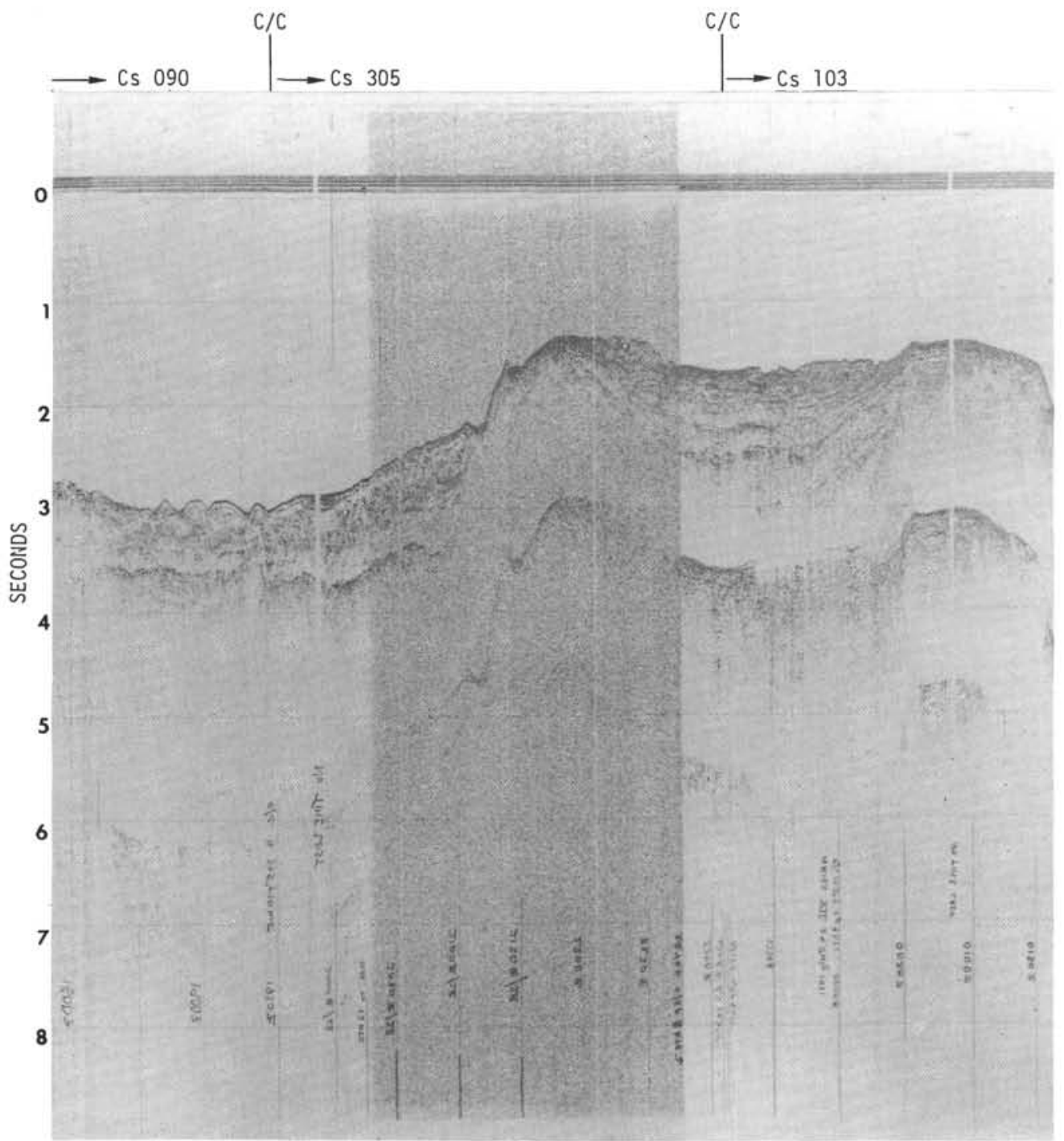

Figure 5. Seismic reflection profiles across Bonin Arc south of Japan (note course changes). 


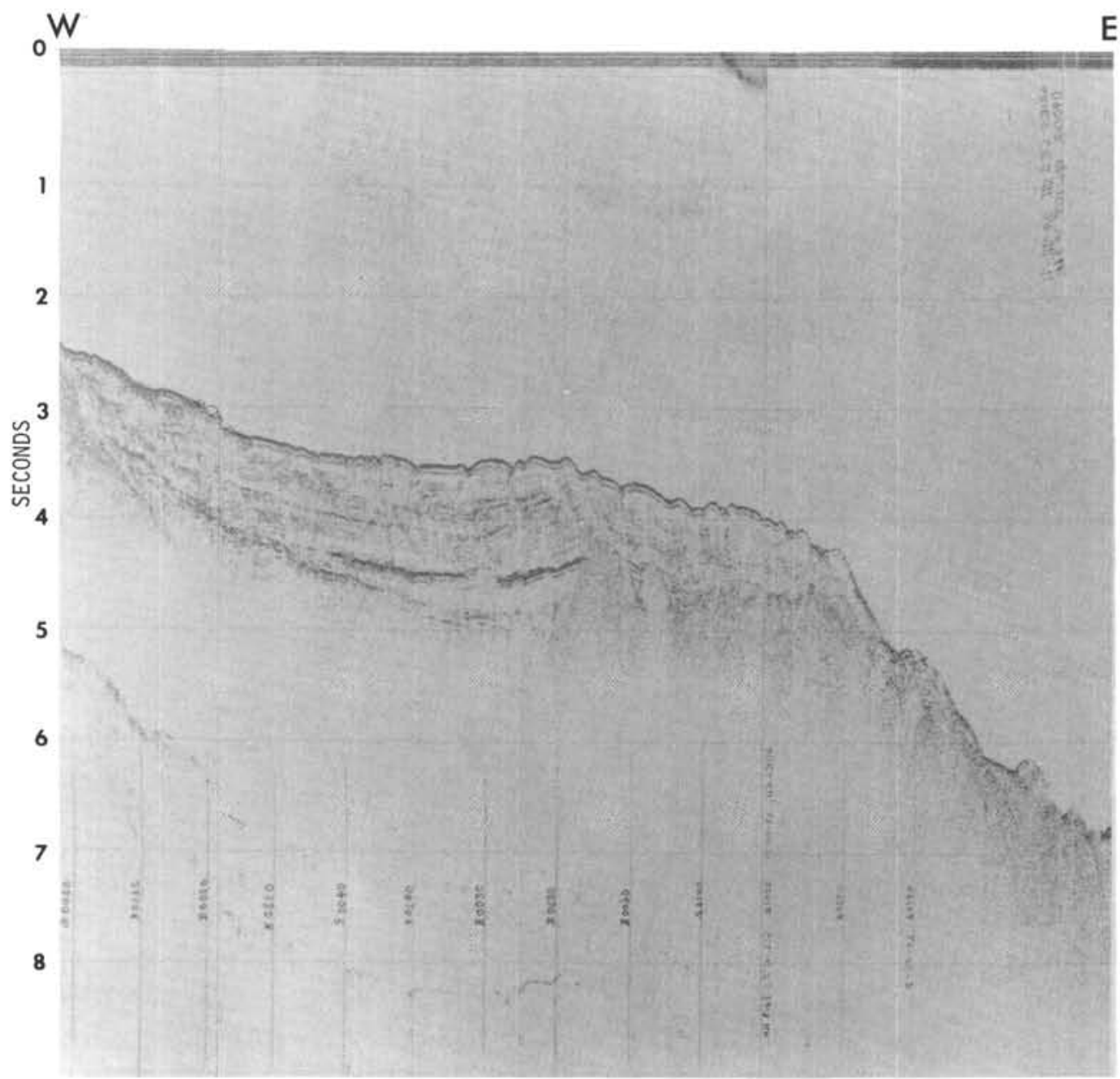

Figure 6. Seismic reflection profile of the east flank of Bonin Arc and west flank of Bonin Trench. 


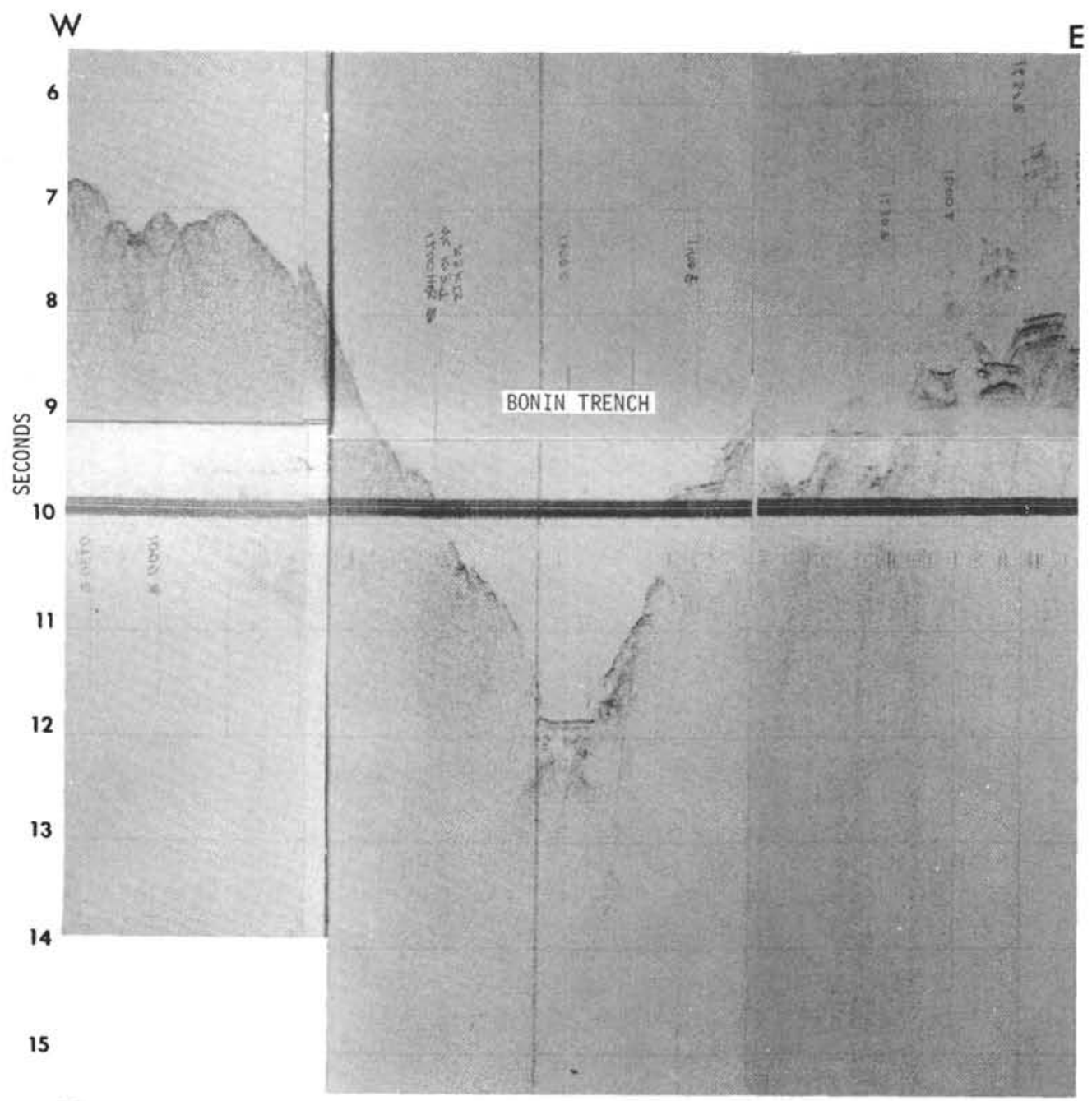

Figure 7. Seismic profile of Bonin Trench. Note absence of sediments on west wall, small sediment pond in trench floor, and sediment layers and basement are displaced by faults on east wall of trench. 


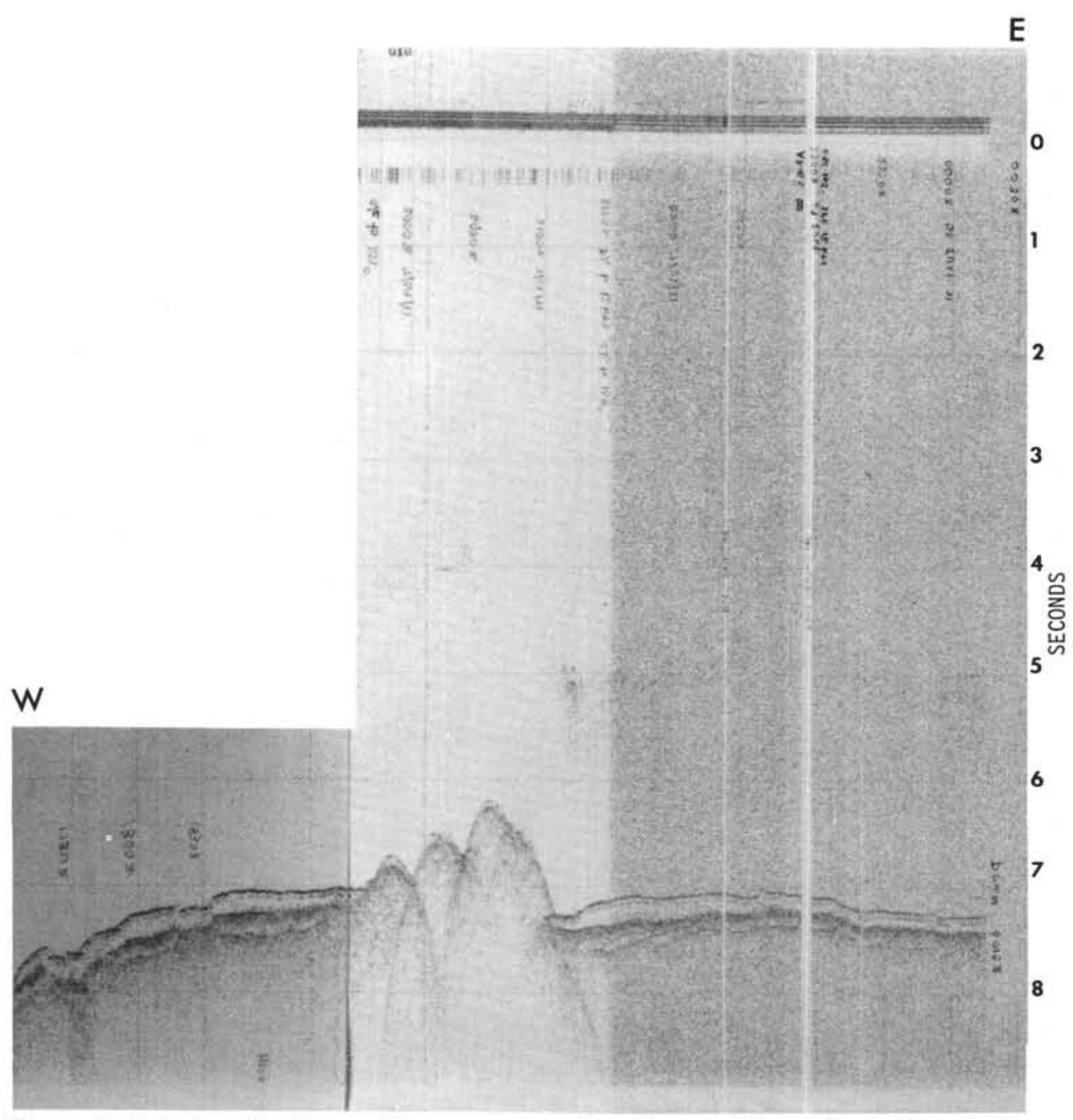

Figure 8. Seismic reflection profile across east wall and outer ridge of Bonin Trench. Note west to east thinning of upper transparent layer. 
T. A. DAVIES

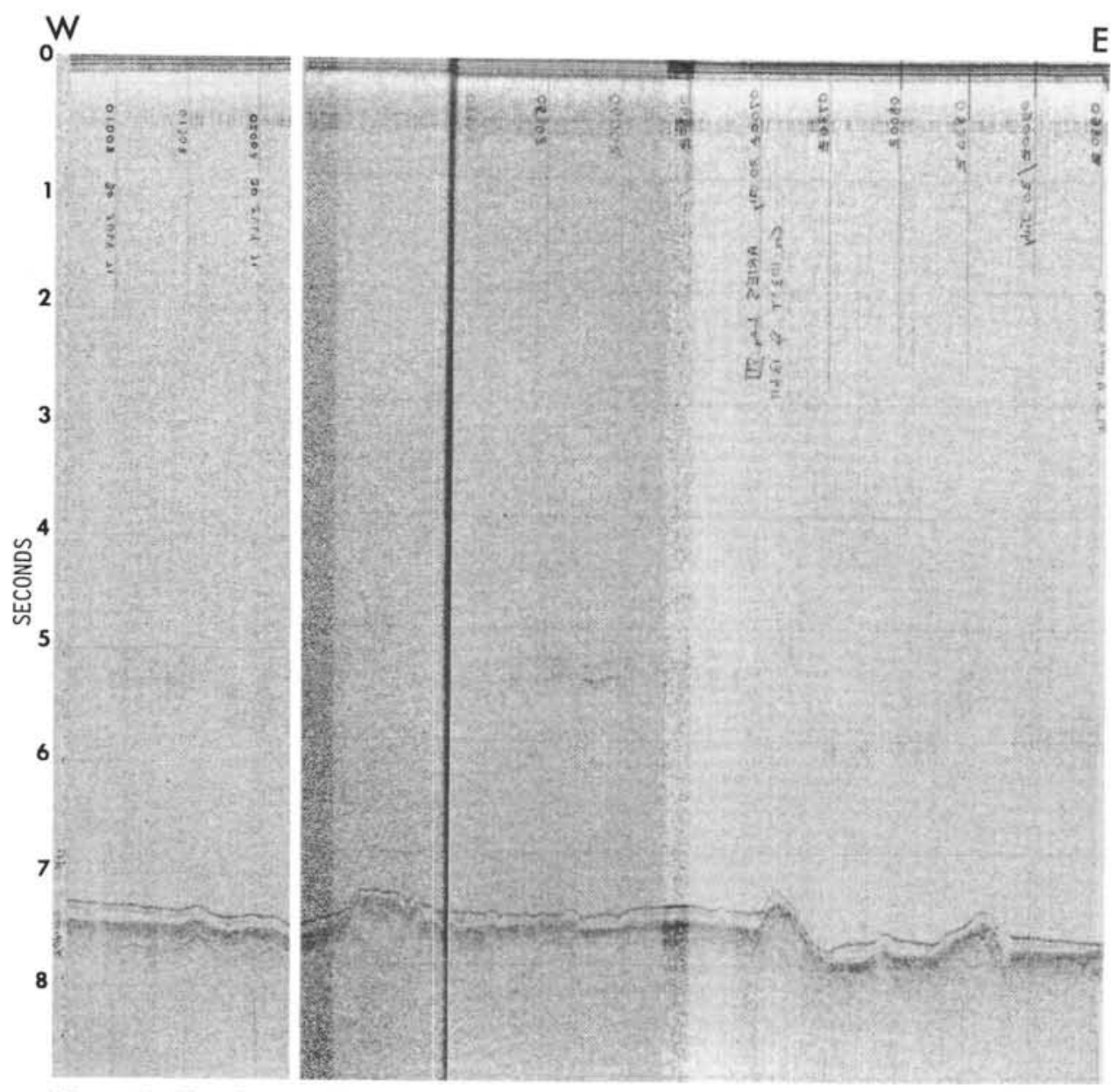

Figure 9. On the east flank of the outer ridge, the seismic reflection profiler fails to penetrate appreciably below the top of the opaque acoustic stratification unit. 


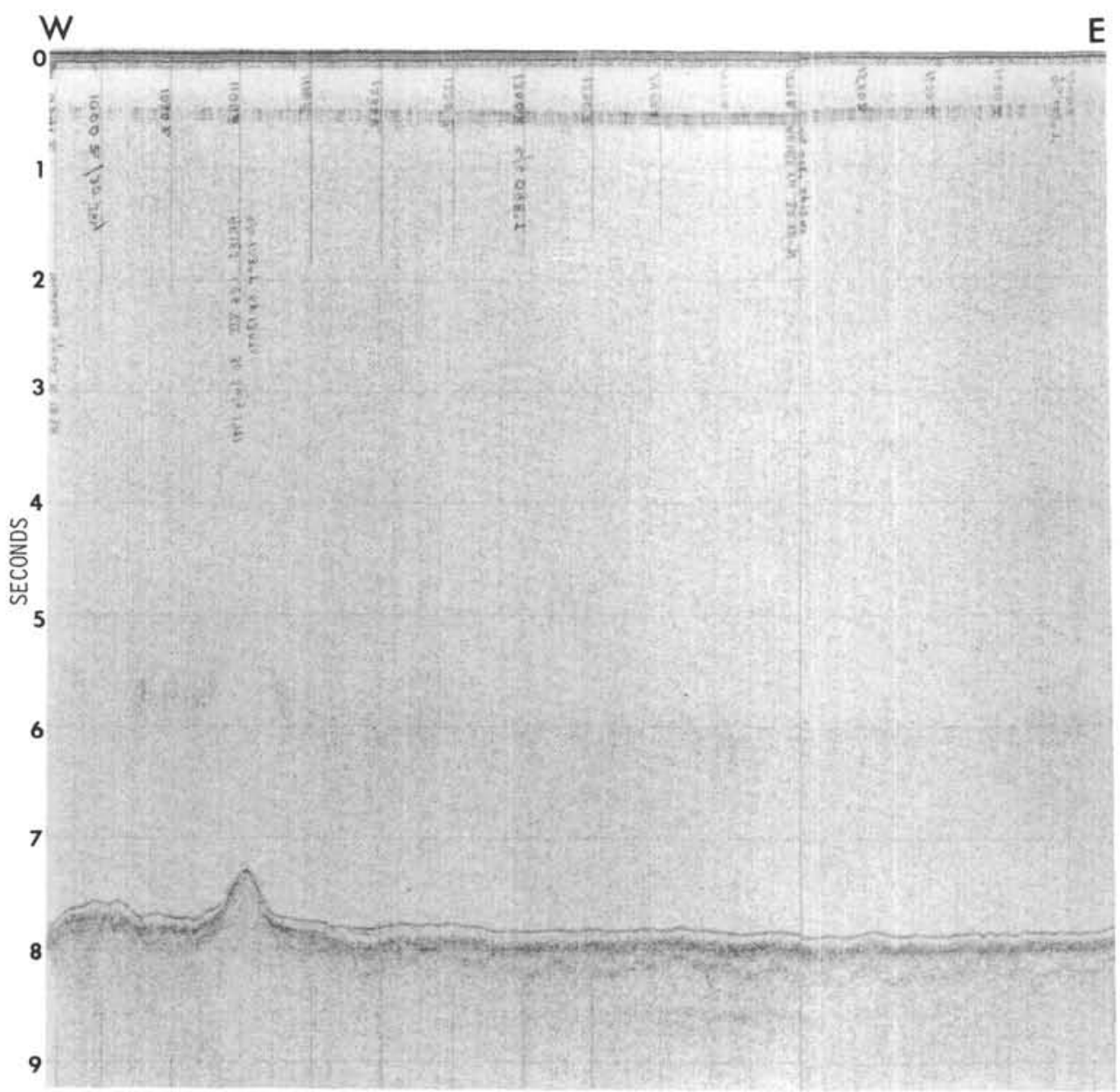

Figure 10. Further out in the basin deeper layers appear within the opaque layer. At least $0.5 \mathrm{~km}$ of sediments is present beneath the transparent layer. The smoothness of the deepest reflector suggests that more sediment lies beneath. 


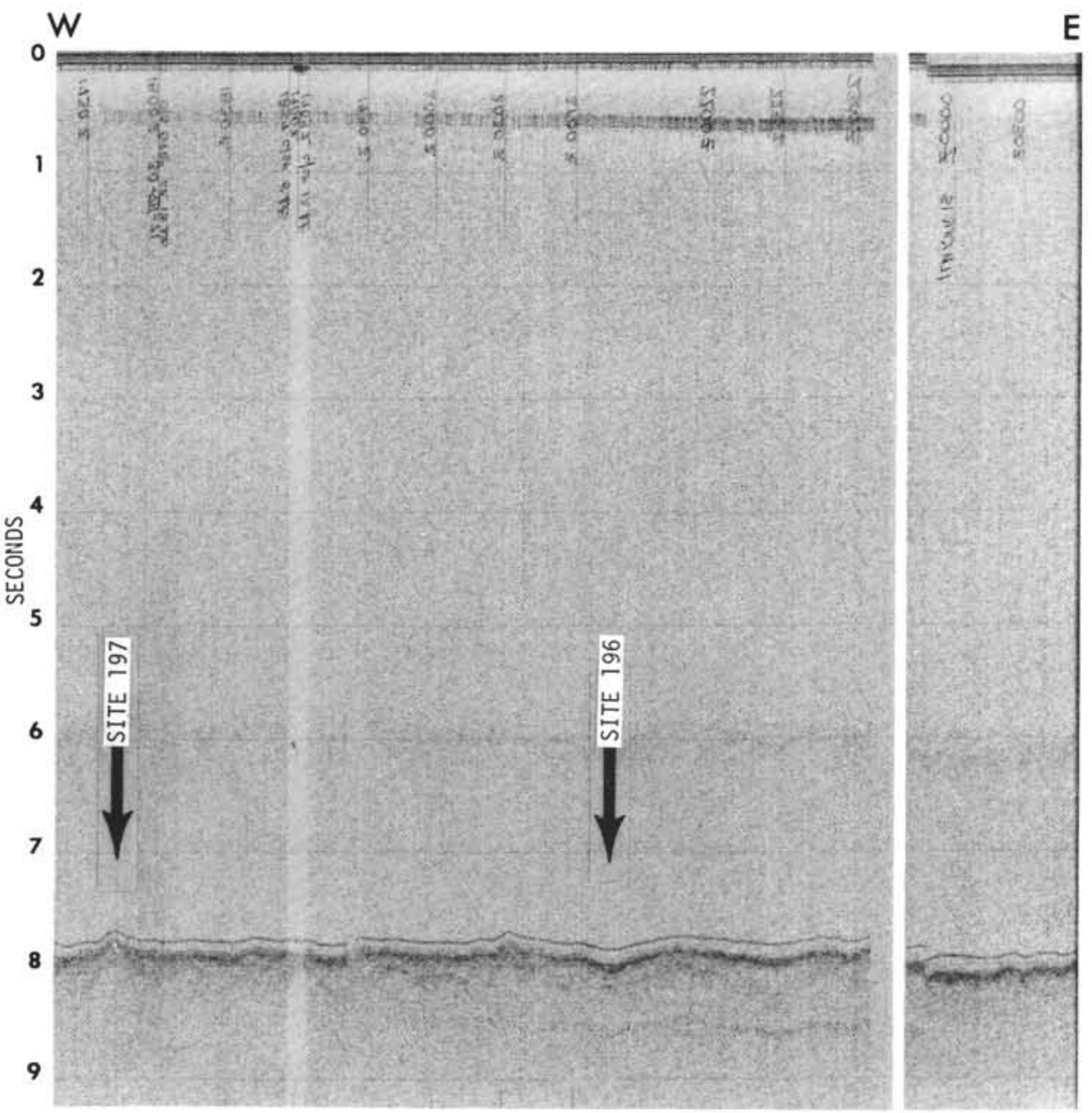

Figure 11. The smooth deep reflector is well recorded at the right center of this figure. Here Hole 196 penetrated 377 meters of chert, chalk, and clay before the bit wore out. The smoothness of the deepest reflector implies that more sediment lies beneath. 


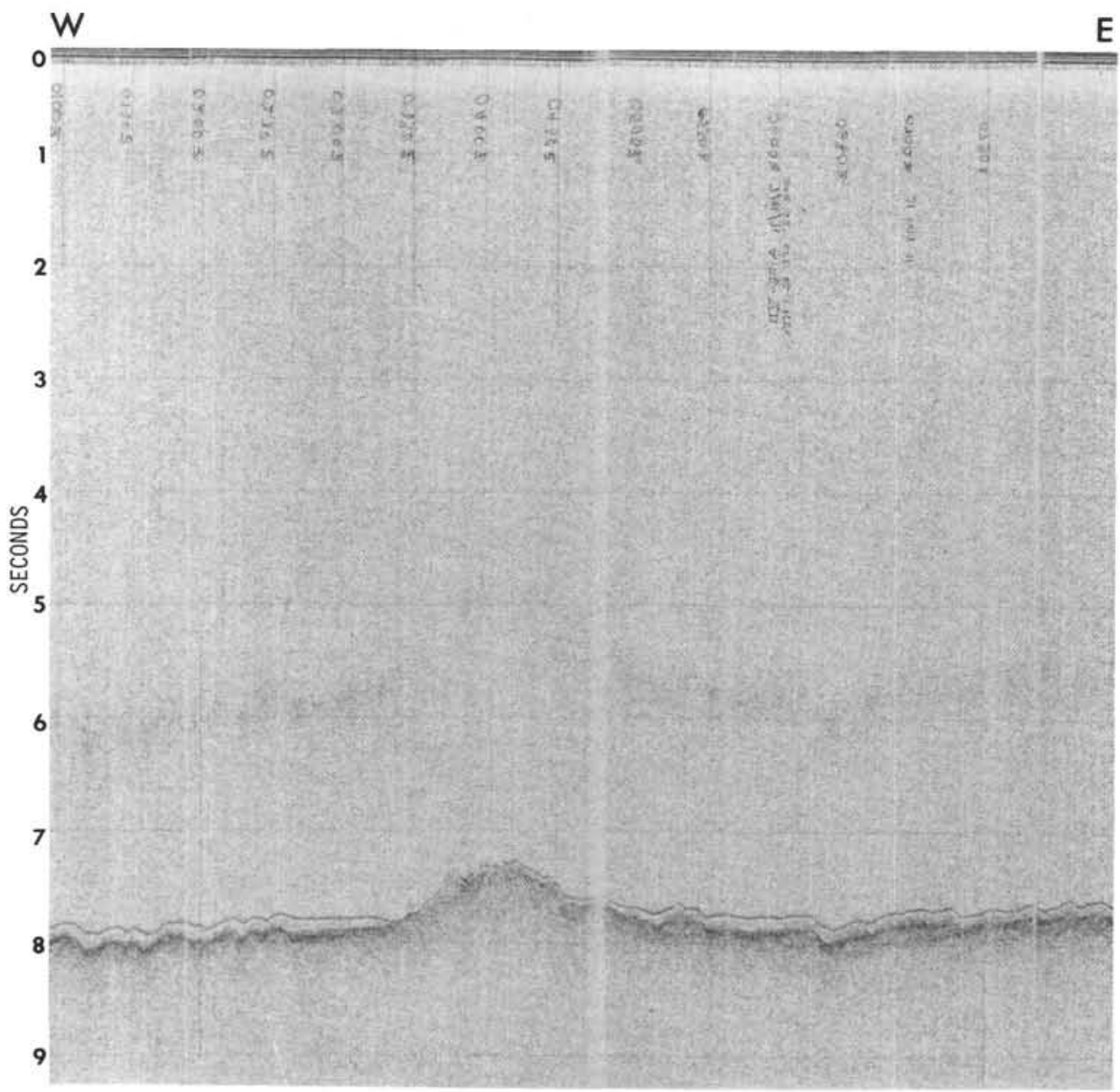

Figure 12. Prominent topographic feature of the basement rises from the abyssal sea floor. 
T. A. DAVIES

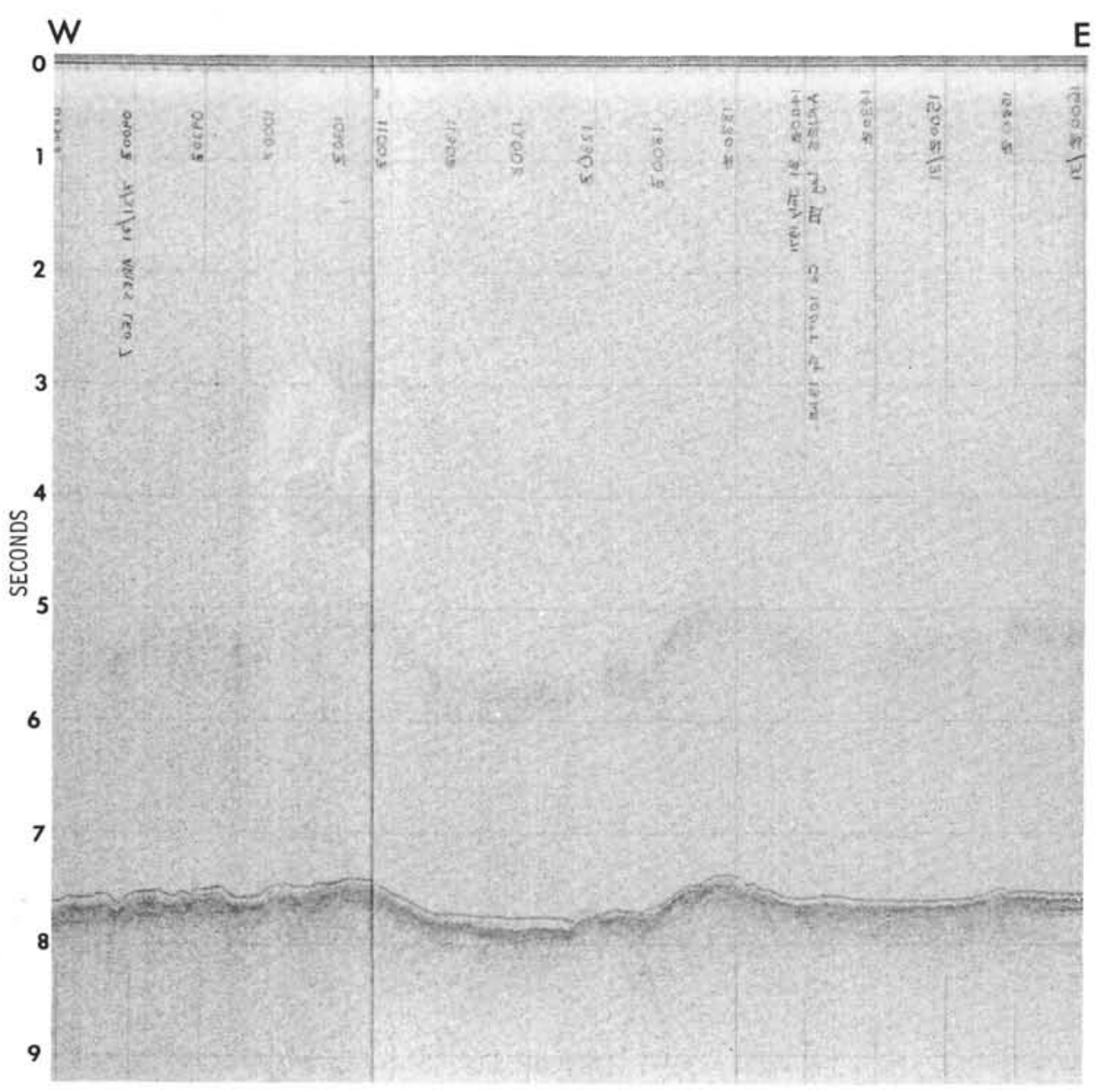

Figure 13. Deepest reflector seen in the previous figures is no longer recorded. The upper transparent layer still provides sufficient thickness for spudding in. 


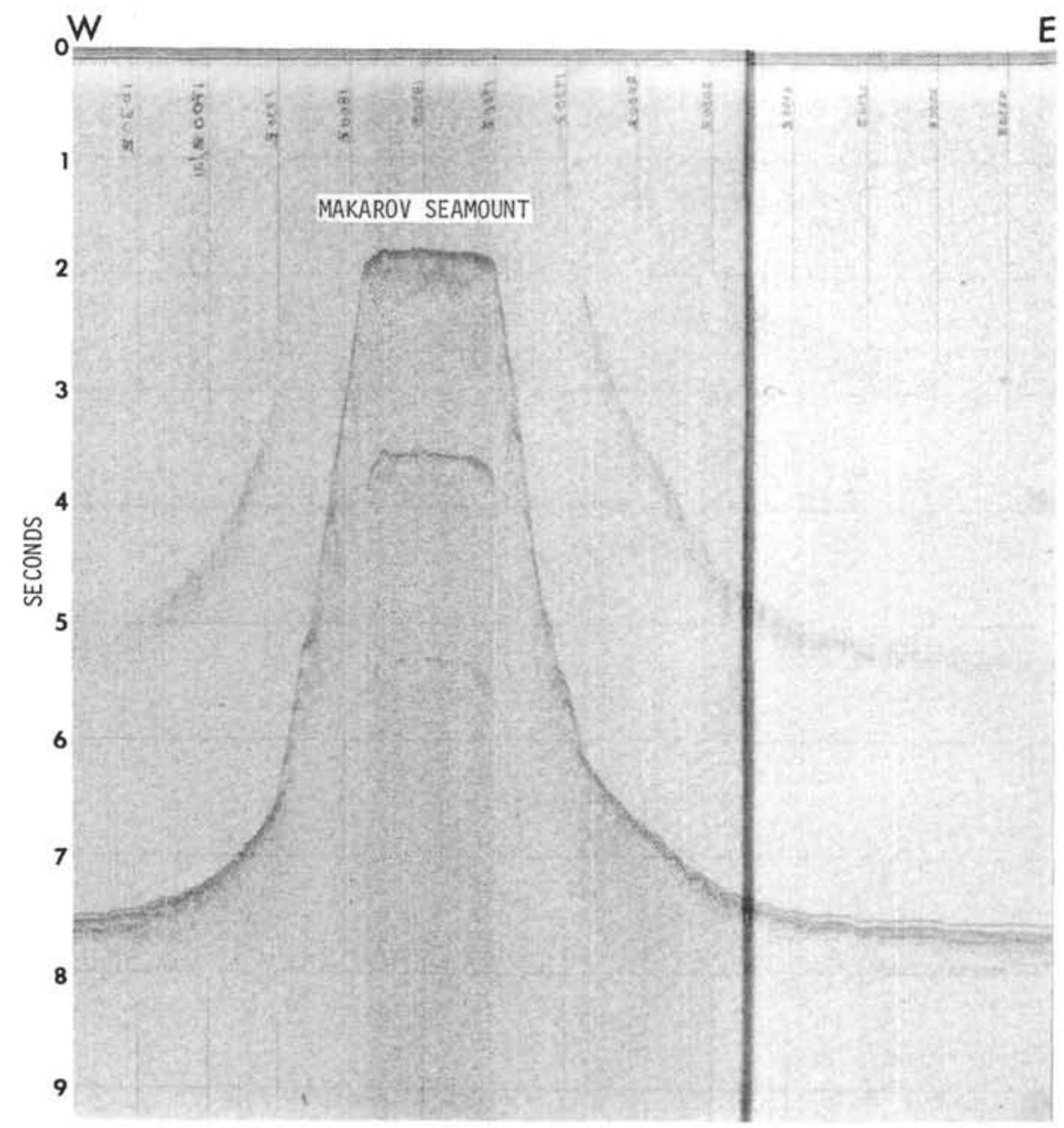

Figure 14. Makarov Seamount. Middle Cretaceous reef material and basalt were dredged here during ARIES V. The deepest reflector recorded on either flank is relatively flat implying the existence of deeper sedimentary units undetected by this profile. 
$160^{\circ} \mathrm{E}$

$161^{\circ} \mathrm{E}$

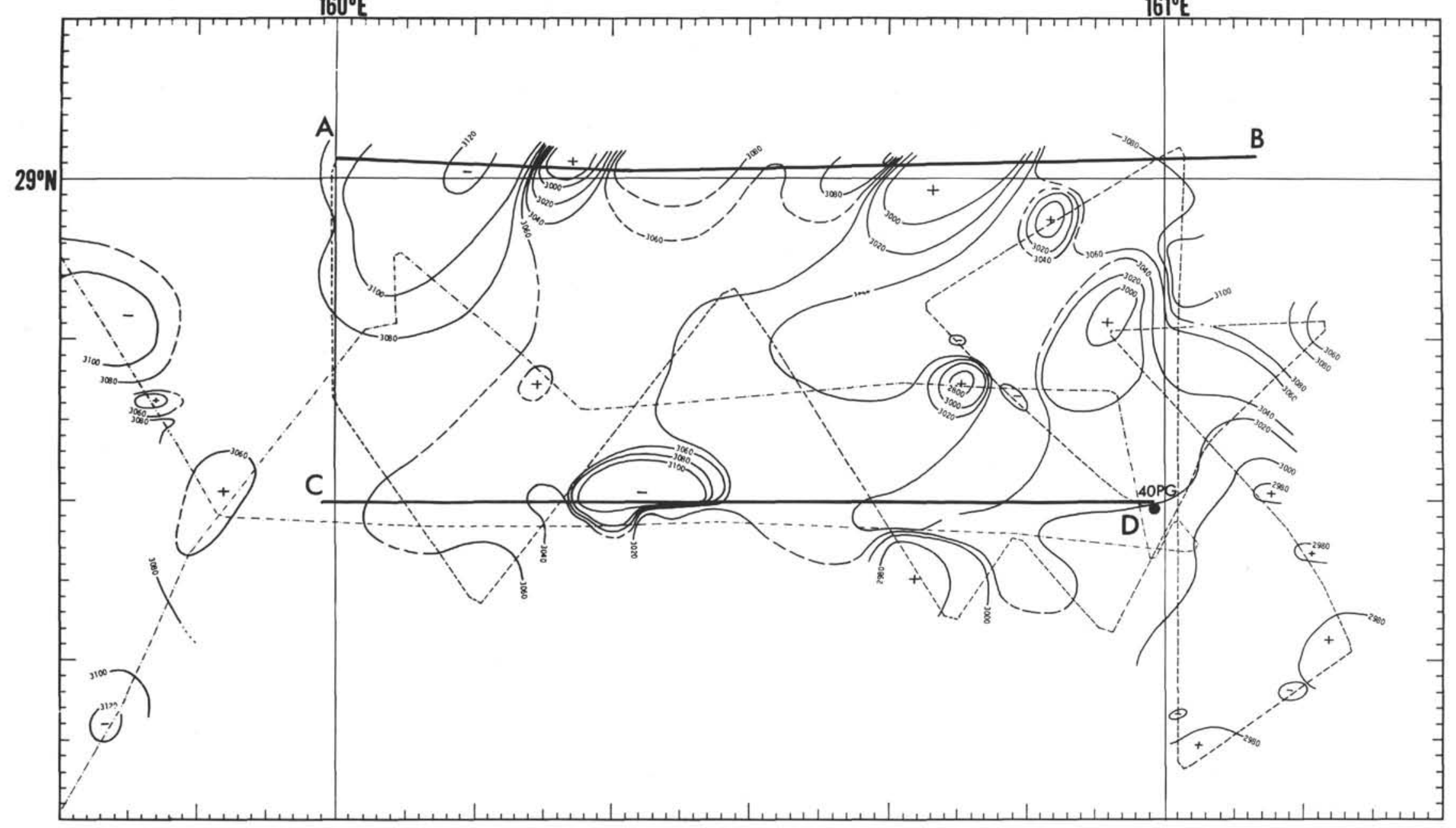




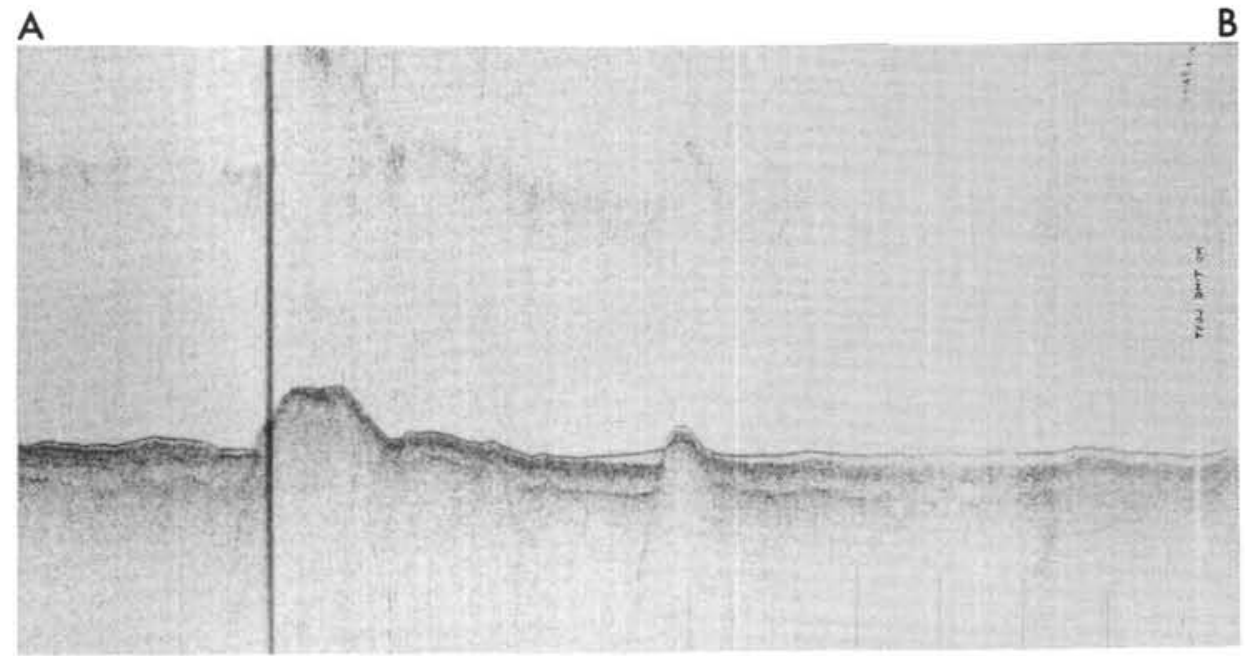

C

B

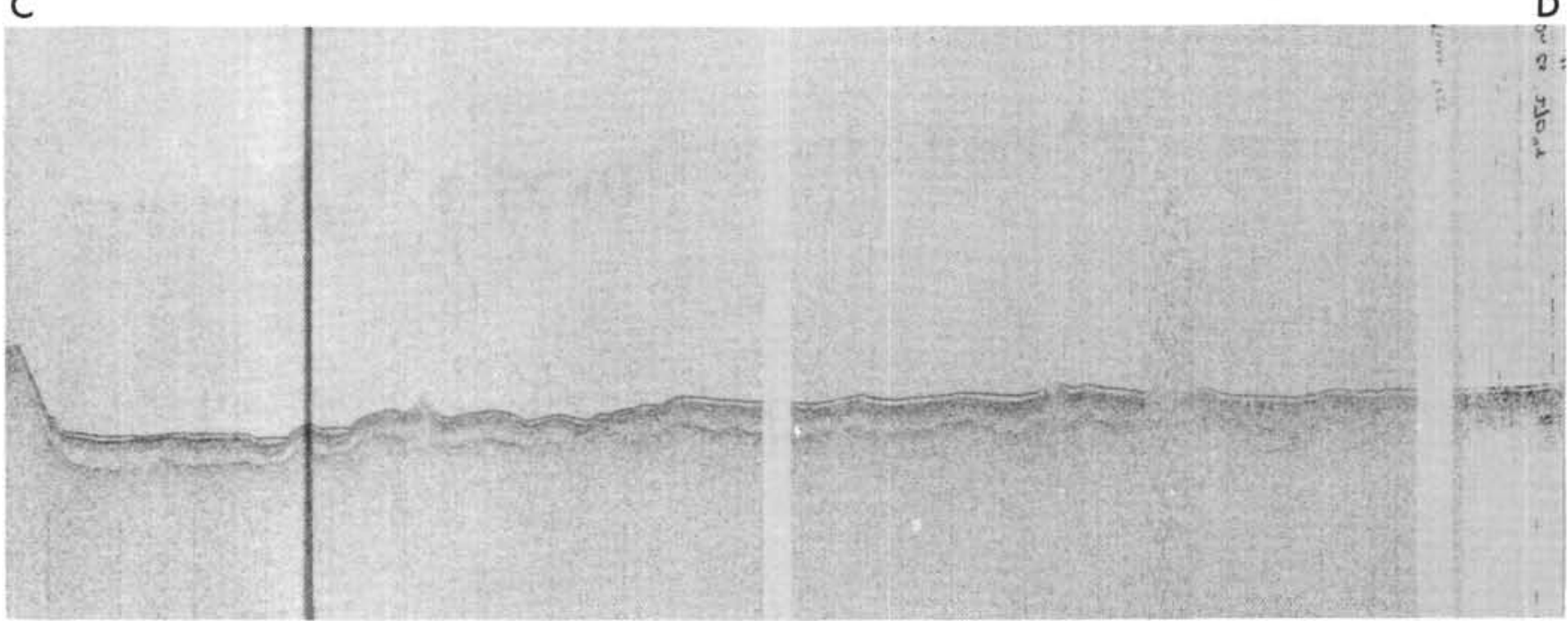

Figure 16. Seismic reflection profiles along lines $A B$ and $C D$, Figure 15. 